\title{
Loggerhead turtles nesting in Libya: an important management unit for the Mediterranean stock
}

\author{
Almokhtar Saied ${ }^{1}$, Fulvio Maffucci ${ }^{2, *}$, Sandra Hochscheid ${ }^{2}$, Salih Dryag ${ }^{1}$, \\ Bashir Swayeb ${ }^{1}$, Marco Borra ${ }^{2}$, Atef Ouerghi ${ }^{3}$, Gabriele Procaccini ${ }^{2}$, \\ Flegra Bentivegna ${ }^{2}$
}

${ }^{1}$ Libyan Sea Turtle Program-Environment General Authority, PO Box 13793, Tripoli, Libya

${ }^{2}$ Stazione Zoologica Anton Dohrn, 80121 Naples, Italy

${ }^{3}$ UNEP-MAP-RAC/SPA, Tunis, Tunisia

\begin{abstract}
Libya is one of the most important loggerhead turtle Caretta caretta nesting grounds in the Mediterranean Sea, but data on its genetic diversity and demographic connection to adjacent Mediterranean nesting sites are scarce. Here we investigated mitochondrial diversity in adult females from 2 nesting locations along the Libyan coasts, Misurata and Sirte, by analysing both the commonly used $380 \mathrm{bp}$ mtDNA fragment and a longer $800 \mathrm{bp}$ fragment that completely encompass the shorter region. No genetic differentiation was detected between the Libyan sites using the shorter sequences $\left(\Phi_{\mathrm{st}}=-0.005, \mathrm{p}=0.54\right.$, Exact $\left.\mathrm{p}=0.67\right)$. However, significant population structuring was found among sites in Libya and other Mediterranean nesting areas $\left(\Phi_{\mathrm{st}}=\right.$ $0.242, \mathrm{p}<0.01)$. The analysis of the longer sequence revealed more haplotypes than the shorter fragment and uncovered genetic differentiation between Misurata and Sirte $\left(\Phi_{\mathrm{st}}=0.13, \mathrm{p}=0.02\right.$, Exact $p=0.01$ ), suggesting fine-scale homing behaviour of loggerhead nesting females along the Libyan coast. Because only a few Atlantic and Mediterranean loggerhead turtle rookeries have been genetically surveyed using the longer sequence, we used information from the short mtDNA fragment to investigate dispersal patterns of Libyan loggerhead turtles. Mixed stock analysis estimates suggested that during the oceanic developmental phase, Libyan juveniles remain preferentially in the eastern Mediterranean while after the transition to the neritic phase, they favour the south Tunisian coastal areas while avoiding the north-central Adriatic Sea. This study highlights the unique nature of the Libyan nesting population, making it an important management unit. The protection of this nesting stock is fundamental to managing the Mediterranean loggerhead turtle assemblage.
\end{abstract}

KEY WORDS: Loggerhead turtle $\cdot$ mtDNA $\cdot$ Population structure $\cdot$ Conservation $\cdot$ Dispersal pattern $\cdot$ Homing

Resale or republication not permitted without written consent of the publisher

\section{INTRODUCTION}

Migratory marine animals often display a complex phylogeographic structure despite high intrinsic individual mobility (Avise 1998, Bowen et al. 2005). Many examples have come to light in which exceptionally high dispersal potential does not translate into high levels of gene flow (Avise 2000). Population structuring may result from a number of different mechanisms related to the biology, ecology and behaviour of a species. For example, foraging specialization and social behaviour have been shown to shape the distribution of genetic variation in killer whales Orcinus orca (Linnaeus, 1758), spinner dolphins Stenella longirostris (Gray, 1828), white sharks Carcharodon carcharias (Linnaeus, 1758) and many 
other marine species (Hoelzel et al. 1998, 2007, Avise 2000, Andrews et al. 2010, Jorgensen et al. 2010). Natal phylopatry (natal homing), i.e. the propensity of adults to return to their birthplace in order to breed, is a common cause of population genetic structure. In particular, if females remain phylopatric to the natal site, the species will be spatially structured along matrilines with a unique genetic signature in terms of female transmitted mitochondrial DNA (mtDNA) and a considerable demographic autonomy for local populations, at least over a short ecological time (Avise 2000). These functionally independent populations are called management units (MUs; Moritz 1994), and their identification is essential to develop proper conservation strategies.

The loggerhead sea turtle Caretta caretta (Linnaeus, 1758) is one of the best-studied species exhibiting natal phylopatry (Bowen et al. 1994, 2005, Encalada et al. 1998, Karl \& Bowen 1999, Bowen \& Karl 2007). This highly migratory marine reptile has a life cycle characterized by an early development in the oceanic zone (oceanic developmental phase), lasting a decade or more, followed by a second developmental stage in the neritic province (neritic developmental phase; Bolten 2003). The switch between these 2 phases, which also implies a dramatic shift in the diet from epipelagic to benthic, is reversible; once loggerhead turtle juveniles have recruited to neritic foraging grounds, they may return to the oceanic environment on shorter time scales, sometimes for several years, for reasons that are still not completely understood (Laurent et al. 1998, Bolten 2003, McClellan \& Read 2007). Foraging aggregations using both the oceanic and the neritic developmental habitats are mixed stocks composed of individuals from widespread populations of nesting females at different beaches, hereafter called rookeries. Upon sexual maturation, loggerhead turtle females begin periodic reproductive migrations to nest in the vicinity of their natal beach (Bowen et al. 2005). Males may undergo similar migrations, although they can mate opportunistically on migratory corridors or coastal foraging grounds (Bowen et al. 2005). Consistent with this natal homing propensity of nesting females, previous mtDNA studies revealed the existence of several demographically independent loggerhead turtle stocks in the AtlanticMediterranean region which differ significantly in mtDNA haplotype frequencies (Encalada et al. 1998, Bowen et al. 2005, Carreras et al. 2007, Garofalo et al. 2009, Monzon-Arguello et al. 2010, Reis et al. 2010, Wallace et al. 2010). The unique mtDNA signature of the nesting groups provides the opportunity to link feeding cohorts to their rookery of origin by using mixed stock analysis (MSA) methods. The accuracy of the estimates, however, is affected by the incomplete survey of all potential source populations, by the level of genetic differentiation among nesting rookeries and by the resolution of the genetic marker (Bolker et al. 2007).

The loggerhead turtle is the most common sea turtle species nesting in the Mediterranean Sea (Casale $\&$ Margaritoulis 2010). The average number of documented nests is over $7200 \mathrm{yr}^{-1}$, mostly from Greece, Cyprus, Turkey and Libya (Casale \& Margaritoulis 2010). As a whole, the Mediterranean population constitutes a regional MU (RMU; Wallace et al. 2010) within which 5 independent MUs have been recognized to date, corresponding to (1) mainland Greece and the adjoining Ionian islands, (2) Turkey, (3) Cyprus, (4) Israel and (5) Calabria (Carreras et al. 2007, Garofalo et al. 2009). This basin is one of the most heavily exploited for recreational or industrial activities worldwide. Each year, tens of thousands of loggerhead turtles are accidentally injured because of the interaction with human activities (Casale \& Margaritoulis 2010). MSA has been used extensively in the Mediterranean Sea to investigate the demographic composition of local foraging grounds in order to understand how threats to these areas impact distant and independent nesting populations (Laurent et al. 1998, Carreras et al. 2006, Maffucci et al. 2006, Casale et al. 2008a, Giovannotti et al. 2010). Although qualitatively informative, all of these studies share 2 common caveats. First, the level of genetic structuring among local nesting populations is lower compared to that reported from the western Atlantic, which is likely the product of recent postglacial colonization of the Mediterranean Sea (18 000-12 000 yr BP; Bowen \& Karl 2007). Second, there is incomplete information on the genetic makeup of the Mediterranean loggerhead turtle rookeries, and in particular, data are missing from Libya, although it has been recognized as 1 of the most important nesting populations in this basin (Margaritoulis et al. 2003, Carreras et al. 2007, Hamza 2010).

Located in the southern part of the Mediterranean Sea, Libya has more than $1000 \mathrm{~km}$ of sandy, pristine coastline that is suitable for loggerhead turtle nesting. The earliest available records on nesting date back to the late 1970s and early 1980s (Armsby 1980, Schleich 1984) but it was only in 1995 that the importance of the Libyan rookery became evident (Laurent et al. 1997). Substantial nesting was discovered in this region, although the overall nesting effort was probably overestimated (Laurent et al. 1997, Mar- 
garitoulis et al. 2003). In 2005, the Environment General Authority (EGA) with the support of the Regional Activity Center for Specially Protected Areas (UNEPMAP-RAC/SPA) launched the Libyan Sea Turtle Program (LibSTP) with the aim of collecting fundamental data on the local loggerhead turtle population and to improve its conservation status. During the last $5 \mathrm{yr}$, monitoring of nesting activity has been conducted by a local team of biologists and volunteers, coordinated by EGA Tripoli, and covers $34 \%$ of the length of Libya's sandy beaches. Nesting appears to be concentrated mainly in 4 regions: the Gulf of Sirte, the region around Benghazi, some sandy beaches of Aljabal Alakhdar (Cyrenaica) and the region of Derna-Tubrok (Hamza 2010). Around 800 nests $\mathrm{yr}^{-1}$ have been detected, and although this monitoring still underestimates the overall nesting effort in the country, it demonstrates the importance of the Libyan nesting rookery within the Mediterranean Sea (Hamza 2010). The predictable intensification of tourism, the development of the coasts and the increasing risk of environmental damage by wastewater and oil pollution pose important threats to the survival of the Libyan loggerhead turtle population. Efforts to manage and monitor this population require information on the level of genetic diversity within the population and its demographic relatedness to adjoining Mediterranean rookeries.

In this study, we analysed mtDNA control region sequence diversity in adult females nesting in 2 distant areas within the Gulf of Sirte nesting region using a longer $800 \mathrm{bp}$ section obtained from newly designed mtDNA control region primers (Abreu-Grobois et al. 2006) that completely encompasses the commonly analysed $380 \mathrm{bp}$ segment. We used the information gathered from this study to reanalyse data from oceanic and neritic loggerhead turtle developmental habitats in the Mediterranean and Atlantic regions by applying the "many-to-many" MSA approach (Bolker et al. 2007). The objectives of this study were to (1) characterize the population structure of the Libyan loggerhead nesting rookeries; (2) define the level of genetic differentiation and demographic autonomy with respect to the other Mediterranean populations; (3) evaluate whether the analysis of longer mtDNA control region sequences allows the identification of variants to the most common and widely shared haplotype CC-A2 which may increase the level of genetic differentiation among Mediterranean loggerhead turtle nesting populations; and (4) investigate the spatial distribution of Libyan loggerhead turtles.

\section{MATERIALS AND METHODS}

\section{Sample collection}

Samples for genetic analysis were collected during the 2009 nesting season from 49 independent nests at 2 nesting areas along the Libyan coast: Misurata ( $\mathrm{n}=$ $14)$ and Sirte $(n=35)$ (Fig. 1). Samples were taken from dead hatchlings that were found during nest excavations conducted by LibSTP biologists as part of the ongoing monitoring project of the loggerhead turtle nesting activity in Libya. Muscle or skin samples were removed from dead hatchlings and stored in $95 \%$ ethanol. Because loggerhead turtles return several times to nest during 1 season, only nests that were laid within $15 \mathrm{~d}$ were considered for the genetic analysis to reduce the risk of pseudo-replication.

\section{Laboratory procedures}

Automation of the genomic DNA extraction method was realised on the Biomek FX workstation (Beckman Coulter) equipped with the ORCA robotic arm using NucleoSpin ${ }^{\circledR} 96$ Tissue (Macherey-Nagel) following the manufacturers' protocols. Genomic DNA was purified by binding and eluting to a silica membrane using vacuum filtration. Excellent DNA quantity, quality genomic DNA and a reduced risk of cross-contamination were achieved using this method.

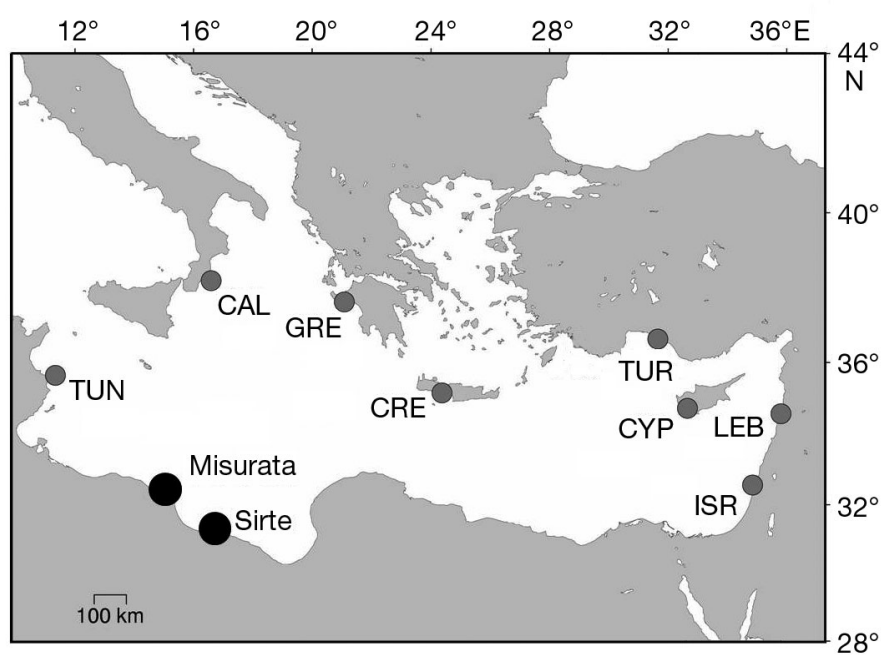

Fig. 1. Caretta caretta. Mediterranean loggerhead turtle nesting units for which molecular information is available. Black circles show the locations sampled in this study. Data for the other nesting areas were derived from the literature. See Table 1 for details on abbreviations and references 
A fragment of mtDNA encompassing tRNA ${ }_{\text {Thr }}$, tRNA $_{\text {Pro }}$ and the control region was amplified by polymerase chain reaction (PCR) using the primers LCM15382 (5'-GCT TAA CCC TAA AGC ATT GG$3^{\prime}$ ) and H950 (5'-GTC TCG GAT TTA GGG GTT TG$3^{\prime}$; Abreu-Grobois et al. 2006). These primers amplify a fragment of $800 \mathrm{bp}$ that completely encompasses the shorter (380 bp) region obtained using the TCR5/TCR6 primer pair, which has been used as a reference to define mtDNA haplotypes in the literature (http://accstr.ufl.edu/ccmtdna.html). PCR reactions were prepared in automation and performed in $50 \mu \mathrm{l}$ volumes using the following conditions: $95^{\circ}$ for $5 \mathrm{~min}$, followed by 35 cycles of $95^{\circ}$ for $1 \mathrm{~min}, 50^{\circ}$ for $1 \mathrm{~min}, 72^{\circ}$ for $1.5 \mathrm{~min}$, and $72^{\circ}$ for $7 \mathrm{~min}$. PCR products were purified in automation using the Millipore Multiscreen HTS PCR 96-Well Plate Kit and sequenced in both directions. Sequence reactions were prepared using BigDye Terminator Cycle Sequencing technology (Applied Biosystems) and purified using the Agencourt CleanSEQ Dye terminator removal kit (Agencourt Bioscience) on the Biomek FX workstation (Beckman Coulter). Products were analysed on an Automated Capillary Electrophoresis Sequencer 3730 DNA Analyzer (Applied Biosystems). Forward and reverse chromatograms of each sample were analysed and assembled using the software package SeqManII (DNASTAR). Resulting sequences were aligned using the Bioedit Sequence Alignment Editor 7.0.9.0 (Hall 1999).

\section{Data analysis}

We performed our analysis both on the short (380 bp) and on the long (800 bp) mtDNA sequences to increase the comparability of our data, since almost all of the information available in the literature on Mediterranean loggerhead turtle nesting populations is based on the shorter fragment.

Mitochondrial segments of $380 \mathrm{bp}$ were classified according to the online haplotype registry that is maintained by the Archie Carr Center for Sea Turtle Research (ACCSTR; http://accstr.ufl.edu/ccmtdna. html). New haplotypes that have not previously been detected in other loggerhead turtle genetic surveys were submitted to ACCSTR to be assigned a code under the standard nomenclature. All statistical analyses were carried out using the statistical software package ARLEQUIN v.3.5.1.2 (Excoffier \& Lischer 2010). Genetic differentiation between the 2 Libyan nesting beaches was verified with the Exact test of population differentiation (Raymond \& Rousset
1995), computed with 100000 steps in the Markov Chain with 10000 dememorization steps, and pairwise $\Phi_{\text {st }}$ (Excoffier et al. 1992) computed with 10000 random permutations. The same statistical analysis was used to compare Libyan rookeries to the other Mediterranean nesting populations for which genetic data were available (Encalada et al. 1998, Laurent et al. 1998, Carreras et al. 2007, Garofalo et al. 2009, Chaieb et al. 2010; Table 1). Sequential Bonferroni correction was not applied because it may increase the likelihood of Type II error for multiple pairwise comparisons (Moran 2003). Standard molecular diversity indices were calculated, and analysis of molecular variance (AMOVA) was performed to determine the partitioning of genetic variation among the different Mediterranean nesting beaches. Correlation between genetic (pairwise $\Phi_{\text {st }}$ ) and geographic distance was assessed using a Mantel test with 10000 permutations. The geographical distances were calculated using Geographic Distance Matrix Generator 1.2.3 (http://biodiversityinformatics.amnh.org/open_source/ gdmg/index.php). In all tests that required estimates of sequence divergence, we used the Tamura-Nei model of nucleotide substitutions, which was designed for control region sequences (Tamura \& Nei 1993)

We used the new information generated by this study to reanalyse previously published data from loggerhead turtle developmental grounds in the Mediterranean Sea and the Atlantic Ocean. A Bayesian MSA based on the many-to-many approach (Bolker et al. 2007) was performed. This approach, contrary to the traditional many-to-one analysis ('foraging centric'), also allows the estimation of the proportion of individuals in each rookery that is going to each foraging ground ('rookerycentric' analysis), thus providing the opportunity to investigate the distribution pattern of Libyan loggerhead turtles during the oceanic and neritic developmental stages. The average annual number of nests were used as a proxy of rookery sizes and incorporated into the analysis as an ecological covariate assuming that the overall contribution of a rookery is proportional to its size (Okuyama \& Bolker 2005). The partitioning of the genetic variation in the source population, oceanic mixed stock and neritic mixed stock datasets were investigated using AMOVA as implemented in ARLEQUIN v.3.5.1.2. (Excoffier \& Lischer 2010). The possible source populations for the MSA were defined among Mediterranean and Atlantic nesting rookeries on the basis of the genetic differentiation as measured by the Exact test of differentiation (Ray- 
Table 1. Caretta caretta. MtDNA haplotype compositions (380 bp sequence), and mean ( \pm SD) haplotype $(h)$ and nucleotide $(\pi)$ diversities detected in Libya compared to the other published Mediterranean nesting areas, with population size (Pop. size), reported as the annual average number of nests. LIB: Libya; CAL: Calabria; TUN: Tunisia; GRE: Greece; CRE: Crete; CYP: Cyprus; TUR: Turkey; ISR: Israel; LEB: Lebanon. Genetic data and nesting population size are drawn from the literature (Laurent et al. 1998, Carreras et al. 2007, Garofalo et al. 2009, Casale \& Margaritoulis 2010)

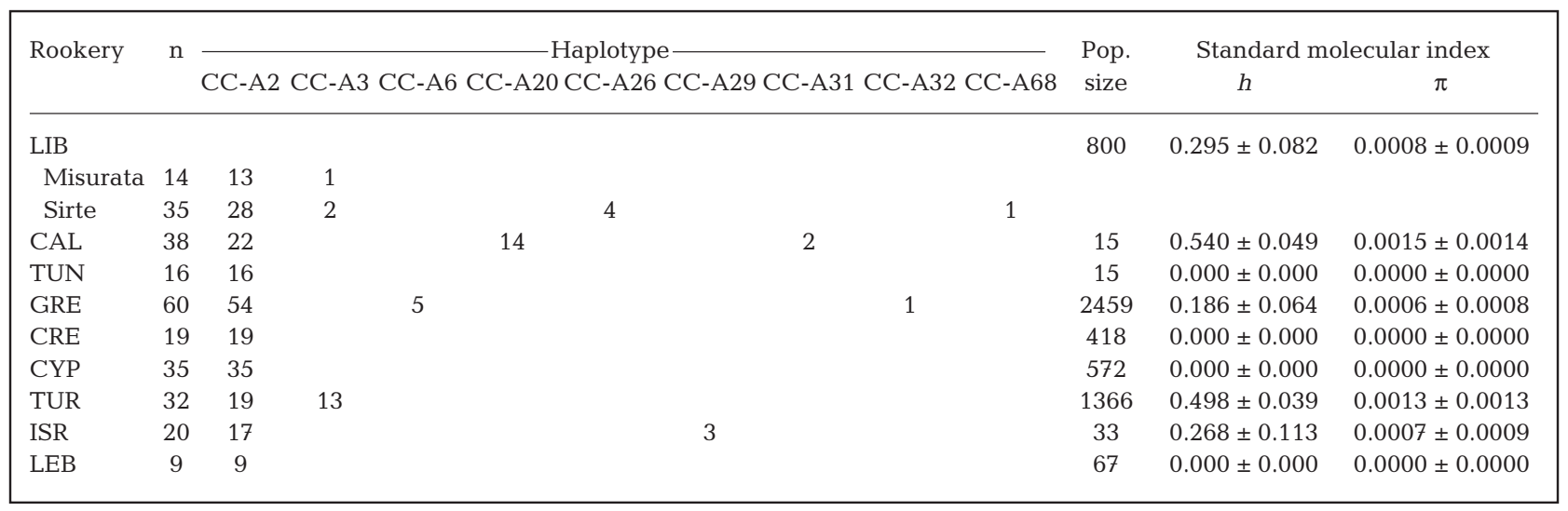

mond \& Rousset 1995). Fourteen rookeries diverged sufficiently in the $380 \mathrm{bp}$ mtDNA haplotype frequency profiles to be used as separate source populations (references are sources of haplotype frequencies): (1) Libya (LIB, $\mathrm{n}=49$ ), (2) Calabria (CAL, $\mathrm{n}=38$; Garofalo et al. 2009), (3) Greece (GRE, $\mathrm{n}=$ 60; Carreras et al. 2007); (4) Mediterranean Islands comprising Cyprus and Crete (M.ISL, $\mathrm{n}=54$; Carreras et al. 2007), 5) Turkey (TUR, $\mathrm{n}=32$; Laurent et al. 1998), (6) Israel (ISR, $\mathrm{n}=20$; Carreras et al. 2007), (7) Cape Verde (CV, n = 187; Monzon-Arguello et al. 2010), (8) Rio de Janeiro/Espírito Santo (Brazil 1, BR1, $\mathrm{n}=114$; Reis et al. 2010), (9) Bahia/Sergippe (Brazil 2, BR2, $\mathrm{n}=76$; Reis et al. 2010), (10) Florida coast/northern Gulf of Mexico (NWFL, $\mathrm{n}=49$; Bowen et al. 2004), (11) South Florida (SFL, $\mathrm{n}=109$; Bowen et al. 2004), (12) northeast Florida to North Carolina (NEF-NC, $\mathrm{n}=105$; Bowen et al. 2004), (13) Dry Tortugas (DT, $\mathrm{n}=58$; Bowen et al. 2004); (14) Quintana Roo, Yucatan, Mexico (YUC, $\mathrm{n}=20$; Bowen et al. 2004); for the complete dataset see Table S1 in the Supplement at www.int-res. com/articles/suppl/m450p207_supp.pdf.

Estimates of rookery size were derived from the literature (Ehrhart et al. 2003, Margaritoulis et al. 2003, Casale \& Margaritoulis 2010, MonzonArguello et al. 2010). Deep genetic structuring was present in the source population dataset (AMOVA $\left.\Phi_{\mathrm{st}}=0.81, \mathrm{p}<0.01\right)$. Two MSAs were performed. First we reanalysed data from the Azores and Madeira (AZ.MA), Strait of Gibraltar region (GIB, Gulf of Cadiz and Alboran Sea), western Mediterranean habitat, corresponding to the drifting longlines fishery area south of the Balearic Islands
(WMED), and eastern Mediterranean habitat (EMED), corresponding to the drifting longlines fishery area south of Lampedusa Island, as representatives of loggerhead turtle juvenile oceanic mixed stocks (Bolten et al. 1998, Laurent et al. 1998, Revelles et al. 2007; see Table S1 for the complete dataset). Second, we considered 6 neritic mixed stocks: north-eastern Spain (NES), south Italy (SIT), north-central Adriatic sea (NCA), Southern Tunisia (ST), Pamlico-Albemarle Estuarine Complex in North Carolina (N.USA) and south Florida (S.USA) (Laurent et al. 1998, Bass et al. 2004, Bowen et al. 2004, Carreras et al. 2006, Maffucci et al. 2006, Giovannotti et al. 2010; see Table S1 for the complete dataset). Oceanic developmental habitats exhibited shallower but still significant genetic structuring compared to neritic habitats (AMOVA, oceanic $\Phi_{\text {st }}=0.078, \mathrm{p}<0.01$, and neritic $\Phi_{\text {st }}=0.333, p<0.01$ ). To distinguish larger from smaller contributions, an arbitrary cut-off value of $5 \%$ was used for the 'foraging centric' estimates (Bolker et al. 2007).

Haplotypes found through the alignment of the longer sequence were classified according to the online haplotype registry maintained by ACCSTR (http://accstr.ufl.edu/cclongmtdna.html). Libyan samples were compared with those from other Mediterranean and Atlantic nesting beaches for which long segment information were available in the literature (Garofalo et al. 2009, Monzon-Arguello et al. 2010; see Table 4). Molecular diversity indices and genetic differentiation between locations were analysed following the same approach used for the short sequences. 


\section{RESULTS}

When the $380 \mathrm{bp}$ sequence segment was considered, no significant differences were detected between the 2 Libyan sampling sites $\left(\Phi_{\mathrm{st}}=-0.005, \mathrm{p}=\right.$ 0.54 , Exact $p=0.67$ ). We therefore pooled all individuals for subsequent analysis. Four distinct haplotypes were observed among the 49 loggerhead turtle nests sampled from Misurata and Sirte. The majority of the individuals were classified as haplotype CC-A2 ( $83.7 \%$ relative frequency); this is the most common mtDNA sequence found on loggerhead turtle nesting beaches in the Mediterranean and Atlantic regions (Table 1). Haplotypes CC-A3 and CC-A26 were found in 6.1 and $8.2 \%$ of individuals, respectively. The former has already been reported in the Mediterranean Sea from a Turkish rookery $(40 \%$ relative frequency), and it is shared with 3 Atlantic nesting units (YUC, NWFL, and SFL; Bowen et al. 2005, Shamblin et al. 2011). Haplotype CC-A26 has not been previously assigned to any nesting area but was detected on several Mediterranean feeding grounds (Laurent et al. 1998, Carreras et al. 2006, Maffucci et al. 2006, Casale et al. 2008a). One individual carried $1 \mathrm{~A}>\mathrm{G}$ transition at position 127 when compared to haplotype $\mathrm{CC}-\mathrm{A} 2$; this represents a previously undiscovered haplotype (CC-A68).

Haplotype diversity $(h)$ was one of the highest reported for the Mediterranean Sea, with only the small Calabrian unit and Turkey exhibiting higher values (Table 1 ). Nucleotide diversity $(\pi)$ was very low but comparable to that reported for other Mediterranean countries (Table 1). Libya was significantly distinct in 4 out of 8 pairwise comparisons, with Greece, Turkey, Calabria and Israel (Table 2). The AMOVA highlighted significant genetic structuring among Mediterranean loggerhead turtle nesting populations $\left(\Phi_{\mathrm{st}}=0.242, \mathrm{p}<0.01\right)$, but no correla- tion between genetic and geographical distance was detected (Mantel test, $r=-0.00027, p=0.71$ ).

The analysis of the longer segment increased the total number of haplotypes detected in the Libyan samples from 4 to 5 . One additional variable site, corresponding to a transition $\mathrm{T}>\mathrm{C}$ at position 121, allowed for the splitting of the common CC-A2 into 2 different haplotypes: CC-A2.1 and CC-A2.9. The first sequence has already been detected on Mediterranean and Atlantic nesting beaches (Garofalo et al. 2009, Monzon-Arguello et al. 2010), while the second has been reported exclusively from Mediterranean foraging areas (Garofalo 2010). Two long sequence haplotypes were assigned for the first time to a rookery of origin, CC-A26.1 and CC-A68.1 (GenBank Accession numbers HQ728521 and JN039304, respectively). Significant differences were found between Libyan sampling locations $\left(\Phi_{\mathrm{st}}=0.13, \mathrm{p}=0.02\right.$, Exact $\mathrm{p}=0.01)$. Mean $( \pm \mathrm{SD})$ haplotype diversity increased to $0.668 \pm 0.037$ and $0.274 \pm 0.148$ for Sirte and Misurata, respectively, while nucleotide diversity was comparable to that calculated from the analysis of the shorter segment (Table 3). Genetic differentiation between Libyan nesting beaches and Calabria, the only other Mediterranean site for which data on the wider mtDNA sequence were available, increased to 0.615 and 0.338 for Sirte and Misurata, respectively.

The Markov chain Monte Carlo (MCMC) method was used to obtain the posterior distributions of the parameters of interest in the many-to-many MSA. Three chains of 30000 iterations were run in each analysis from over-dispersed points using as the dominant starting points Libya, Greece and eastern Turkey. The Gelman-Rubin diagnostic criterion was $<1.2$ for all variables indicating the convergence of MCMC. When considering oceanic developmental habitats, the many-to-many estimation identified

Table 2. Caretta caretta. Genetic differentiation (mean \pm SD) between Mediterranean loggerhead turtle nesting rookeries obtained with the $380 \mathrm{bp}$ mtDNA sequence. Above the diagonal are the Exact test of population differentiation values, below the diagonal are the $\Phi_{\text {st }}$ values (significant values with $\mathrm{p}<0.05$ are shown in bold). Rookery abbreviations as in Table 1

\begin{tabular}{|c|c|c|c|c|c|c|c|c|c|}
\hline Rookery & y LIB & CAL & TUN & GRE & CRE & CYP & TUR & ISR & LEB \\
\hline LIB & & $0.000 \pm 0.000$ & $0.604 \pm 0.008$ & $0.001 \pm 0.000$ & $0.513 \pm 0.013$ & $0.089 \pm 0.005$ & $0.001 \pm 0.000$ & $0.041 \pm 0.007$ & $1.000 \pm 0.0000$ \\
\hline CAL & 0.245 & & $0.002 \pm 0.001$ & $0.000 \pm 0.000$ & $0.002 \pm 0.001$ & $0.001 \pm 0.000$ & $0.000 \pm 0.000$ & $0.001 \pm 0.000$ & $0.088 \pm 0.006$ \\
\hline GRE & 0.037 & 0.353 & -0.030 & & $0.488 \pm 0.009$ & $0.153 \pm 0.008$ & $0.000 \pm 0.000$ & $0.014 \pm 0.003$ & $1.000 \pm 0.000$ \\
\hline $\mathrm{CRE}$ & 0.011 & 0.239 & 0.000 & -0.024 & & $-1.000 \pm 1.000$ & $0.001 \pm 0.001$ & $0.235 \pm 0.004$ & $-1.000 \pm 1.000$ \\
\hline CYP & 0.033 & 0.300 & 0.000 & -0.01 & 0.000 & & $0.000 \pm 0.000$ & $0.043 \pm 0.003$ & $-1.000 \pm 1.000$ \\
\hline LEB & -0.026 & 0.181 & 0.000 & -0.058 & 0.000 & 0.000 & 0.257 & 0.037 & \\
\hline
\end{tabular}




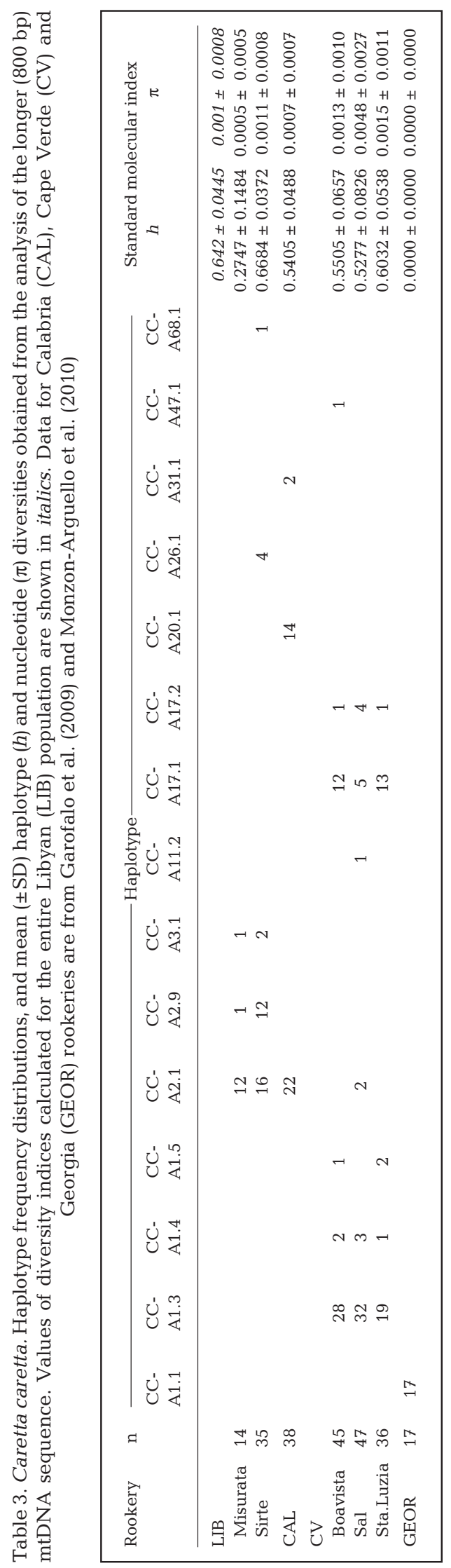

only 3 contributions from Mediterranean rookeries above the arbitrary cut-off value of $5 \%$ (Table 4 ). The presence of Atlantic individuals drops drastically on Mediterranean neritic habitats with only 5 out of 32 contributions above the cut-off value (Table 4).

The rookery-centric estimates suggest that Libyan loggerhead juveniles preferentially remain in the eastern Mediterranean during the oceanic phase (EMED: $44 \pm 18 \%$ ), with all other areas exhibiting similar proportions of individuals from this population (AZ.MA: $12 \pm 11 \%$; GIB: $14 \pm 13 \%$; WMED: $16 \pm$ $13 \%$; unknown: $14 \pm 12 \%$ ) (Fig. 2). As neritic juveniles and adults they disperse throughout the entire basin, although their abundance is significantly higher in the ST $(27 \pm 12 \%)$, NES $(22 \pm 11 \%)$ and SIT $(20 \pm 11 \%)$ than in NCA $(9 \pm 8 \%$; Fig. 2$)$. The estimated proportion of neritic juveniles from Libya going to western Atlantic foraging habitats is always below $10 \%$ (N.USA: $7 \pm 7 \%$; S.USA: $8 \pm 7 \%$; unknown: $8 \pm 8 \%$ ) (Fig. 2).

\section{DISCUSSION}

The advantage gained from the long mtDNA sequence over the short sequence was immediately tangible when investigating genetic differences of the 2 relatively close nesting areas in Libya. The analysis of the conventional short sequence suggested that females nesting at the 2 Libyan sites belonged to a unique population. Several other nesting locations in the Mediterranean Sea, such as those on mainland Greece and the adjoining Ionian Islands, or Crete and Cyprus, were also found to be genetically indistinguishable when using the short mtDNA sequence as the molecular marker (Carreras et al. 2007). The relatively recent colonization of the Mediterranean Sea may have produced an apparent panmixia where mutation rates were not fast enough to show up in the short mtDNA sequence, although demographic partitions may still exist (Encalada et al. 1998, Reece et al. 2005, Bowen \& Karl 2007, Carreras et al. 2007). Moreover, the low sample size from Misurata may have led to a further reduction of statistical power in detecting differentiation between the 2 locations using this molecular marker (Roberts et al. 2004). In fact, loggerhead turtle females have also been shown to be capable of homing on a relatively fine scale in this basin as demonstrated by the strong genetic structuring of nesting populations along the Turkish coasts (Schroth et al. 1996). Additionally, tagging studies have suggested that the interchange of females among nesting beaches is 
Table 4. Caretta caretta. Foraging-centric estimated contributions (mean \pm SD) of the different oceanic and neritic habitats considered in this study. Contributions above the cut-off value of $5 \%$ are reported in bold. LIB: Libya; CAL: Calabria; GRE: Greece; M.ISL: Mediterranean Islands comprising Cyprus and Crete; TUR: Turkey; ISR: Israel; CV: Cape Verde; BR1: Rio de Janeiro/ Espírito Santo; BR2: Bahia/Sergippe; DT: Dry Tortugas; YUC: Quintana Roo, Yucatan; NWFL: Florida coast/northern Gulf of Mexico; NEF-NC: northeast Florida to North Carolina; SFL: South Florida; NES: north eastern Spain; SIT: southern Italy; NCA: north central Adriatic; ST: southern Tunisia; S./N. USA: southern/northern US Atlantic coast; AZ.MA: Azores and Maderia; GIB: Strait of Gibraltar; W/EMED: western/eastern Mediterranean

\begin{tabular}{|c|c|c|c|c|c|c|c|c|c|c|}
\hline \multirow[t]{2}{*}{ Rookery } & \multicolumn{6}{|c|}{-Neritic habitats- } & \multicolumn{4}{|c|}{ _-Oceanic habitats- } \\
\hline & NES & SIT & $\mathrm{NCA}$ & $\mathrm{ST}$ & S.USA & N.USA & AZ.MA & GIB & WMED & EMED \\
\hline \multicolumn{11}{|c|}{ Mediterranean } \\
\hline LIB & $15 \pm 7.8$ & $14 \pm 7.2$ & $5.3 \pm 4.8$ & $20.1 \pm 9.1$ & $0.3 \pm 0.4$ & $0.3 \pm 0.4$ & $0.8 \pm 0.8$ & $0.6 \pm 0.6$ & $0.9 \pm 1.3$ & $5.1 \pm 4$ \\
\hline CAL & $0.5 \pm 0.5$ & $0.8 \pm 0.6$ & $0.4 \pm 0.4$ & $0.5 \pm 0.5$ & $0 \pm 0$ & $0 \pm 0$ & $0.1 \pm 0$ & $0.1 \pm 0.1$ & $0.1 \pm 0.1$ & $0.1 \pm 0.1$ \\
\hline GRE & $17.1 \pm 11.2$ & $40.5 \pm 12$ & $51 \pm 11.4$ & $43.8 \pm 14$ & $0.6 \pm 0.8$ & $0.7 \pm 0.7$ & $1.9 \pm 2$ & $1.9 \pm 1.9$ & $5.6 \pm 7.6$ & $6.7 \pm 6.6$ \\
\hline M.ISL & $17.7 \pm 10.8$ & $12.6 \pm 9.4$ & $10.1 \pm 8.1$ & $16.9 \pm 11.9$ & $90.4 \pm 0.6$ & $0.5 \pm 0.6$ & $1.1 \pm 1.1$ & $0.9 \pm 0.9$ & $1.7 \pm 2.6$ & $2.9 \pm 3.2$ \\
\hline TUR & $9.3 \pm 5.2$ & $11.3 \pm 5.3$ & $13.4 \pm 5.9$ & $12.9 \pm 5.8$ & $0.4 \pm 0.5$ & $0.3 \pm 0.3$ & $1.4 \pm 1.3$ & $0.7 \pm 0.7$ & $0.9 \pm 1.2$ & $2.5 \pm 2.7$ \\
\hline ISR & $1.2 \pm 0.8$ & $0.5 \pm 0.4$ & $0.4 \pm 0.4$ & $0.5 \pm 0.4$ & $0 \pm 0$ & $0 \pm 0$ & $0.1 \pm 0.1$ & $0.1 \pm 0.1$ & $0.1 \pm 0.1$ & $0.1 \pm 0.1$ \\
\hline \multicolumn{11}{|l|}{ Atlantic } \\
\hline $\mathrm{CV}$ & $2 \pm 1.9$ & $1.9 \pm 1.8$ & $1.6 \pm 1.6$ & $0.9 \pm 0.9$ & $2.1 \pm 2.1$ & $1.3 \pm 1.3$ & $6.5 \pm 4.6$ & $8.1 \pm 5.6$ & $3 \pm 2.9$ & $3.9 \pm 3.6$ \\
\hline BR1 & $0.9 \pm 0.9$ & $0.9 \pm 0.8$ & $1.6 \pm 1.6$ & $0.8 \pm 0.8$ & $0.7 \pm 0.7$ & $0.5 \pm 0.5$ & $0.7 \pm 0.7$ & $0.9 \pm 0.9$ & $1.4 \pm 1.3$ & $1.8 \pm 1.7$ \\
\hline BR2 & $0.9 \pm 0.9$ & $0.9 \pm 0.9$ & $1.5 \pm 1.4$ & $0.9 \pm 0.9$ & $0.7 \pm 0.7$ & $0.5 \pm 0.4$ & $0.8 \pm 0.7$ & $0.9 \pm 0.9$ & $1.6 \pm 1.5$ & $1.9 \pm 1.9$ \\
\hline DT & $2.5 \pm 2.2$ & $2.2 \pm 2$ & $1.9 \pm 1.7$ & $2.4 \pm 2.1$ & $0.1 \pm 0.2$ & $0.2 \pm 0.2$ & $0.3 \pm 0.2$ & $0.2 \pm 0.2$ & $0.2 \pm 0.4$ & $0.6 \pm 0.6$ \\
\hline YUC & $6.6 \pm 6.1$ & $3.9 \pm 4.7$ & $6.1 \pm 6.7$ & $6.7 \pm 7$ & $3.3 \pm 2.7$ & $2.8 \pm 1.5$ & $4.1 \pm 2.1$ & $2.4 \pm 1.4$ & $1 \pm 1.2$ & $3.1 \pm 2.6$ \\
\hline NWFL & $4.6 \pm 3.8$ & $2.9 \pm 2.4$ & $1.8 \pm 1.8$ & $1.1 \pm 1.1$ & $0.7 \pm 0.8$ & $0.8 \pm 0.7$ & $0.8 \pm 0.8$ & $0.6 \pm 0.6$ & $0.6 \pm 0.9$ & $1.6 \pm 1.8$ \\
\hline NEF-NC & $3.7 \pm 3$ & $2.6 \pm 2.2$ & $1.5 \pm 1.5$ & $0.9 \pm 0.9$ & $3.1 \pm 3.1$ & $20.1 \pm 7.6$ & $13.8 \pm 7.5$ & $7.9 \pm 5.6$ & $2.9 \pm 3.2$ & $4.6 \pm 4.4$ \\
\hline SFL & $18 \pm 9.2$ & $5.2 \pm 4.6$ & $3.5 \pm 3.6$ & $1.8 \pm 1.8$ & $87.6 \pm 6.9$ & $71.9 \pm 9.4$ & $67.8 \pm 10.6$ & $74.8 \pm 8.8$ & $80.1 \pm 14.8$ & $65.1 \pm 17.7$ \\
\hline
\end{tabular}

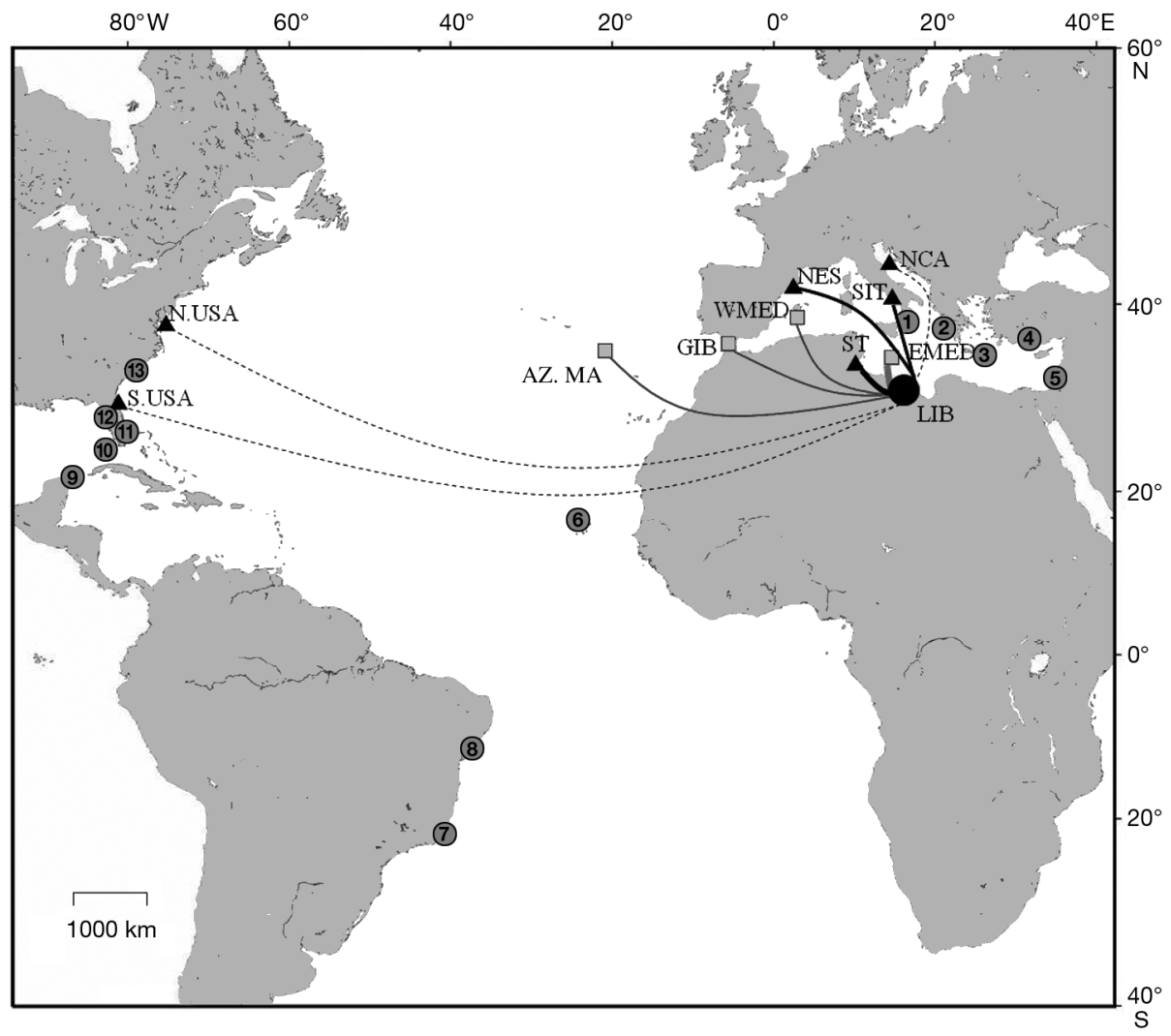

Fig. 2. Caretta caretta. Dispersal pattern of loggerhead turtles from Libya as inferred by rookery-centric analysis: line thickness is proportional to the fraction of turtles going from Libya to each oceanic (square) and neritic (triangle) foraging ground. Dotted lines show pathways representing less than $10 \%$ of the intake of a given foraging ground. Grey circles represent the source populations used in the 2 mixed stock analyses: (1) CAL, (2) GRE, (3) M.ISL, (4) TUR, (5) ISR, (6) CV, (7) BR2, (8) BR1, (9) YUC, (10) DT, (11) SFL, (12) NWFL, (13) NEF-NC (site abbreviations as in Table 4) 
restricted both in number and geographical range (Margaritoulis 1997). The panmixia suggested by the short sequence analysis was not confirmed when the longer mtDNA fragment was analysed. The 2 Libyan nesting areas were found to be genetically distinct mainly because of the splitting of common haplotype CC-A2 into 2 sub-haplotypes, CC-A2.1 and CC-A2.9, thus exhibiting different frequency distributions (Table 3). The first, CC-A2.1, is the most frequent long subtype reported in the Atlantic loggerhead turtle nesting stock, where 7 long variants of CC-A2 have been found to date (http://accstr.ufl.edu/ cclongmtdna.html); this subtype is also the only one described in Calabria (Garofalo et al. 2009, MonzonArguello et al. 2010, Nielsen 2010). The natal origin of CC-A2.9 was not known, but this variant was recently found in juvenile and adult loggerhead turtles from the North Adriatic Sea and the Gulf of Gabes, which are 2 of the most important neritic foraging grounds in the Mediterranean basin and, based on previous MSA results, are used almost exclusively by local individuals (Garofalo 2010, Giovannotti et al. 2010, Karaa et al. 2011). This finding, along with the absence of this haplotype in the Atlantic loggerhead turtle stock, suggests that CCA2.9 evolved in the Mediterranean Sea from the shared subtype CC-A2.1.

Apart from the ubiquitous and very common CCA2, 3 other short haplotypes were found (Table 1). One, CC-A3, detected at both nesting locations at comparable frequencies ( $7 \%)$, is shared with Mediterranean and Atlantic rookeries (Laurent et al. 1998, Bowen et al. 2005, Carreras et al. 2006, Shamblin et al. 2011) and differs from CC-A2 by a single transitional substitution. This has caused some debate regarding its mono- or polyphyletic origin in the Mediterranean and Atlantic regions (Carreras et al. 2007). By enlarging the reading frame, it appeared that the Libyan subtype corresponded to the most common Atlantic variant CC-A3.1 (Nielsen 2010), but this did not help in resolving the ambiguity, since the extra sequence analysed was identical to the common and shared CC-A2.1. However, the now larger geographical distribution of CC-A3 in the Mediterranean Sea may be explained by the combination of founder effect and restricted gene flow among nesting beaches due to natal phylopatry of females consistent with the arrival of this variant from Western Atlantic colonies during the colonization of the Mediterranean Sea as hypothesized by Schroth et al. (1996). Another short haplotype, CCA26, was found exclusively in Sirte. This sequence had been previously reported from several Mediter- ranean foraging habitats, but it could not be used in the MSA since the rookery of origin was still unknown (Laurent et al. 1998, Carreras et al. 2006, Maffucci et al. 2006, Casale et al. 2008a). The analysis of the extra sequence in the longer fragment revealed that the subtype CC-A26.1 originated from a single mutation from the variant CC-A2.9, which strongly suggested a local origin. In previous genetic surveys of Mediterranean loggerhead turtle nesting beaches, 4 other endemic short-sequence haplotypes were described (CC-A6, CC-A29, CCA31, CC-A32; Carreras et al. 2007, Garofalo et al. 2009), but none of them has been reported as consistently as CC-A26 from local foraging grounds in both the eastern and western part of the basin. This finding confirms the relative importance of Libya in the Mediterranean context and suggests that the size of its population may be significantly higher than that currently reported by the nesting beach monitoring programme (Hamza 2010). Finally, 1 individual from Sirte carried a previously unknown haplotype (CC-A68), differing by a single mutation from CC-A2, thus contributing a unique Libyan haplotype profile (Table 1). The finding of such a rare haplotype emphasizes once again the importance of analysing a significant number of samples from each nesting beach to get accurate haplotype frequency distributions.

Both the relatively high molecular diversity (Tables 1 \& 3) and results from the genetic differentiation tests (Table 2) make a strong case that loggerhead turtles nesting in Libya form at least 1 relevant MU (Moritz 1994) for the Mediterranean loggerhead turtle aggregation. The significant difference in haplotype frequencies between sampling sites, detected by the analysis of the longer mtDNA fragment, suggests that this nesting region (Gulf of Sirte) may support 2 functionally independent rookeries that should be considered as different MUs. However, more samples from the Misurata area are necessary to confirm such genetic differentiation. Moreover, it would be important to collect additional samples from the other 3 Libyan nesting regions in order to investigate how mitochondrial genetic diversity is distributed along the Libyan coast. The global level of population structuring within this basin and the increased level of genetic differentiation among Sirte, Misurata and Calabria, highlighted by the analysis of the long mtDNA fragment, collectively suggest the existence of fine-scale homing behaviour of loggerhead turtle females in the Mediterranean Sea with demographically distinct nesting areas that are separated by only a few hundred kilometres (Schroth et al. 1996, Bowen 
\& Karl 2007). This clearly emphasizes the importance of reinforcing the protection of all Mediterranean loggerhead turtle nesting beaches since even small units, such as the Calabrian one, are unlikely to be reestablished by immigration from other local nesting beaches if extirpated by human activities, at least over ecological time scales (Avise 2000).

Recently, MSA software has become more sophisticated and now incorporates the effects of sampling error and source population sizes and provides the opportunity to investigate migratory connectivity in a meta-population made up of multiple sources and multiple mixed stocks (Bolker et al. 2003, 2007, Okuyama \& Bolker 2005). The approach used here is a refinement of the already complex many-to-one method employed in previous studies which explains why foraging-ground-centric estimates were qualitatively similar to those reported in the literature (Carreras et al. 2006, Maffucci et al. 2006, Bolker et al. 2007, Giovannotti et al. 2010). Atlantic individuals constitute the vast majority of oceanic stage juveniles in the Mediterranean foraging habitats analysed, but they are very 'rare' in the local coastal waters with the only exception of north-eastern Spain (Table 4). This suggests that they may preferentially leave the area at a later stage to recruit to neritic habitats closer to their natal region consistent with the juvenile natal phylopatry behaviour suggested by Bowen et al. (2004). Foraging-centric analysis estimated only 3 contributions from Mediterranean rookeries to local oceanic habitats above the arbitrary cut-off value of $5 \%$ (Table 4); this implies that mortality in these areas impacts almost exclusively the distant Atlantic populations.

Rookery-centric results suggested that juveniles from the Libyan population remain preferentially in the eastern Mediterranean basin during the oceanic developmental phases (estimated rookery-centric contribution for EMED = $44 \pm 18 \%$; Fig. 2). One possible scenario is that hatchlings entering the sea from Libya are entrained in the strong eddies characteristic of the local surface circulation pattern and drift passively in the eastern Mediterranean basin (Hamad et al. 2006). In a recent current-simulation dispersal analysis performed on floating seeds of the seagrass Posidonia oceanica, the existence of a west-to-east passive dispersal, due to the dominant patterns of marine currents, was clearly demonstrated (Serra et al. 2010). Similarly, offspring from the Libyan rookery, as well as other Mediterranean MUs, may disperse during the first years much farther east than the eastern Mediterranean habitat considered here, drifting passively with the sea surface currents, but to date these developmental habitats have neither been identified nor sampled. Loggerhead juveniles from Libya may then reach the western Mediterranean basin only after several years when they have grown to a reasonable size and have improved their swimming ability, meaning that even the strong surface current of the Strait of Gibraltar would not be a barrier to their departure from the Mediterranean Sea into the Atlantic Ocean (Revelles et al. 2007; Fig. 2). At the time of the transition to the neritic stage, Libyan juveniles seem to select foraging grounds closer to their natal beach such as southern Tunisia while avoiding other areas such as the northcentral Adriatic Sea (NCA), although this is known to be one of the most important neritic foraging grounds in the Mediterranean (Fig. 2). Juvenile natal phylopatry (Bowen et al. 2004) cannot completely explain the estimated distribution of Libyan neritic turtles within the Mediterranean Sea, probably because of the reduced distances among the considered foraging grounds. Recently, it has been suggested that loggerhead turtles imprint on potential future foraging sites during the initial years of hatchling dispersal (Hays et al. 2010). If this is the case, the circulation pattern in the eastern Mediterranean (Hamad et al. 2006) which has been previously hypothesized to shape the dispersal of Libyan oceanic stage juveniles in the Mediterranean Sea, may also account for the distribution described here. However, 2 caveats must be considered when interpreting MSA results: first, the large degree of overlap of the short mtDNA haplotype frequency distributions among rookeries makes them only weakly informative when inferring turtle movements (Bolker et al. 2007), and second, the possibility that the boundary between oceanic and neritic foraging aggregations in the Mediterranean Sea is not as precise as considered in this analysis. Because of the very small distance involved in this region compared to the Atlantic Ocean, there is a high probability that oceanic juveniles occasionally enter nearby neritic areas and that adults or large juveniles may cross oceanic habitats during their reproductive migrations or movement between foraging areas, respectively (Casale et al. 2008b). The coupling of MSA with other techniques such as stable isotope analysis, which may help to identify the life stage of sampled individuals, is recommended for the future to get a more precise picture of the demographic structure of juvenile loggerhead turtle aggregations in the Mediterranean Sea.

The new information provided by this study fills an important gap in our knowledge of loggerhead turtle population structure in the Mediterranean Sea. Libya 
hosts an important loggerhead turtle $\mathrm{MU}$, and the protection of this assemblage is fundamental to conserving the Mediterranean stock as a whole. This study also provided evidence of fine-scale homing behaviour of nesting females along the Libyan coastline. The genetic distinctiveness of the 2 areas must be taken into consideration to avoid modifying the genetic structure of this population through management activities. Rookery-centric analysis suggested that surface circulation may influence the dispersal pattern of loggerhead turtles from Libya during the early phase of development and may also play a relevant role for the selection of foraging sites at a later stage. Finally, the promising results obtained by the analysis of the longer mtDNA fragment which allows us to uncover genetic differentiation between the 2 sampling locations, call for the expansion of genetic surveys of Mediterranean nesting beaches as well as foraging grounds using this marker. This added information should increase the accuracy of MSA; this is a critical component of good management plans and conservation strategies.

Acknowledgements. We gratefully thank LibSTP personnel for their contributions to sampling and field work. We also thank the members of the staff of Molecular Biology service of the Stazione Zoologica for their assistance in the analysis of the samples. This study was part of a long-term cooperation between LibSTP, Stazione Zoologica of Naples and UNEP-MAP-RAC/SPA. We acknowledge use of the Maptool (www.seaturtle.org) programme for figures in this paper.

\section{LITERATURE CITED}

Abreu-Grobois FA, Horrocks JA, Formia A, Dutton PH and others (2006) New mtDNA D-loop primers which work for a variety of marine turtle species may increase the resolution capacity of mixed stock analysis. In: Frick M, Panagopoulous A, Rees A, William K (eds) 26th Annu Symp Sea Turtle Biol Conserv. International Sea Turtle Society, Athens, p 179

Andrews KR, Karczmarski L, Au WWL, Rickards SH and others (2010) Rolling stones and stable homes: social structure, habitat diversity and population genetics of the Hawaiian spinner dolphin (Stenella longirostris). Mol Ecol 19:732-748

Armsby JK (1980) Kouf National Park marine survey final report: April-July, 1980. Arab Center for the Study of Arid Zones and Dry Lands, Beida

- Avise JC (1998) Conservation genetics in the marine realm. J Hered 89:377-382

Avise JC (2000) Phylogeography: the history and formation of species. Harvard University Press, Cambrige, MA, and London

- Bass AL, Epperly SP, Braun-McNeill J (2004) Multi-year analysis of stock composition of a loggerhead turtle (Caretta caretta) foraging habitat using maximum likelihood and Bayesian methods. Conserv Genet 5:783-796
Bolker B, Okuyama T, Bjorndal K, Bolten A (2003) Sea turtle stock estimation using genetic markers: accounting for sampling error of rare genotypes. Ecol Appl 13:763-775

Bolker BM, Okuyama T, Bjorndal KA, Bolten AB (2007) Incorporating multiple mixed stocks in mixed stock analysis: 'many-to-many' analyses. Mol Ecol 16:685-695

Bolten A (2003) Variation in sea turtle life history patterns: neritic vs oceanic developmental stages. In: Lutz $P$, Musick JA, Wyneken J (eds) The biology of sea turtles, Vol II. CRC Press, Boca Raton, FL, p 243-258

Bolten AB, Bjorndal KA, Martins HR, Dellinger T, Biscoito MJ, Encalada SE, Bowen BW (1998) Transatlantic developmental migrations of loggerhead sea turtles demonstrated by mtDNA sequence analysis. Ecol Appl 8:1-7

> Bowen BW, Karl SA (2007) Population genetics and phylogeography of sea turtles. Mol Ecol 16:4886-4907

> Bowen BW, Kamezaki N, Limpus CJ, Hughes GR, Meylan AB, Avise JC (1994) Global phylogeography of the loggerhead turtle (Caretta caretta) as indicated by mitochondrial DNA haplotypes. Evolution 48:1820-1828

Bowen BW, Bass AL, Chow SM, Bostrom M and others (2004) Natal homing in juvenile loggerhead turtles (Caretta caretta). Mol Ecol 13:3797-3808

Bowen BW, Bass AL, Soares L, Toonen RJ (2005) Conservation implications of complex population structure: lessons from the loggerhead turtle (Caretta caretta). Mol Ecol 14:2389-2402

> Carreras C, Pont S, Maffucci F, Pascual M and others (2006) Genetic structuring of immature loggerhead sea turtles (Caretta caretta) in the Mediterranean Sea reflects water circulation patterns. Mar Biol 149:1269-1279

> Carreras C, Pascual M, Cardona L, Aguilar A and others (2007) The genetic structure of the loggerhead sea turtle (Caretta caretta) in the Mediterranean as revealed by nuclear and mitochondrial DNA and its conservation implications. Conserv Genet 8:761-775

Casale P, Margaritoulis D (2010) Sea turtles in the Mediterranean Sea: distributions, threats and conservation priorities. IUCN, Gland

> Casale P, Freggi D, Gratton P, Argano R, Oliverio M (2008a) Mitochondrial DNA reveals regional and interregional importance of the central Mediterranean African shelf for loggerhead sea turtles (Caretta caretta). Sci Mar 72: 541-548

> Casale P, Abbate G, Freggi D, Conte N, Oliverio M, Argano R (2008b) Foraging ecology of loggerhead sea turtles Caretta caretta in the central Mediterranean Sea: evidence for a relaxed life history model. Mar Ecol Prog Ser 372:265-276

Chaieb O, Ouaer A, Maffucci F, Bradai MN, Bentivegna F, Said K, Chatti N (2010) Genetic survey of loggerhead turtle Caretta caretta nesting population in Tunisia. Mar Biodiv Rec 3:e20

Ehrhart LM, Bagley DA, Redfoot WE (2003) Loggerhead turtles in the Atlantic Ocean: geographic distribution, abundance, and population status. In: Bolten AB, Witherington BE (eds) Loggerhead sea turtles. Smithsonian Institution, Washington, DC, p 157-174

Encalada SE, Bjorndal KA, Bolten AB, Zurita JC and others (1998) Population structure of loggerhead turtle (Caretta caretta) nesting colonies in the Atlantic and Mediterranean as inferred from mitochondrial DNA control region sequences. Mar Biol 130:567-575

> Excoffier L, Lischer HEL (2010) Arlequin Suite ver 3.5: a new series of programs to perform population genetics analy- 
ses under Linux and Windows. Mol Ecol Resour 10: 564-567

Excoffier L, Smouse P, Quattro JM (1992) Analysis of molecular variance inferred from metric distances among DNA haplotypes: application to human mitochondrial DNA restriction data. Genetics 131:479-491

Garofalo L (2010) The genetics of the loggerhead turtle (Caretta caretta) in Italy: from scientific data to public knowledge. PhD thesis, University of Rome

Garofalo L, Mingozzi T, Mico A, Novelletto A (2009) Loggerhead turtle (Caretta caretta) matrilines in the Mediterranean: further evidence of genetic diversity and connectivity. Mar Biol 156:2085-2095

Giovannotti M, Franzellitti S, Cerioni PN, Fabbri E and others (2010) Genetic characterization of loggerhead turtle (Caretta caretta) individuals stranded and caught as bycatch from the North-Central Adriatic Sea. AmphibReptilia 31:127-133

Hall TA (1999) BioEdit: a user-friendly biological sequence alignment editor and analysis program for Windows 95/98/NT/2000/XP. Nucl Acids Symp Ser 41:95-98

Hamad N, Millot C, Taupier-Letage I (2006) The surface circulation in the eastern basin of the Mediterranean Sea. Sci Mar 70:457-501

Hamza A (2010) Libya. In: Casale P, Margaritoulis D (eds) Sea turtles in the Mediterranean Sea: distribution, threats and conservation priorities. IUCN, Gland, p 157-170

> Hays GC, Fossette S, Katselidis KA, Mariani P, Schofield G (2010) Ontogenetic development of migration: Lagrangian drift trajectories suggest a new paradigm for sea turtles. J R Soc Interface 7:1319-1327

Hoelzel AR, Dahlheim M, Stern SJ (1998) Low genetic variation among killer whales (Orcinus orca) in the eastern North Pacific and genetic differentiation between foraging specialists. J Hered 89:121-128

> Hoelzel AR, Hey J, Dahlheim ME, Nicholson C, Burkanov V, Black N (2007) Evolution of population structure in a highly social top predator, the killer whale. Mol Biol Evol 24:1407-1415

Jorgensen SJ, Reeb CA, Chapple TK, Anderson S and others (2010) Philopatry and migration of Pacific white sharks. Proc Biol Sci 277:679-688

Karaa S, Maffucci F, Bradai MN, Bentivegna F, Said K, Chatti N (2011) Demographic composition of the Tunisian loggerhead foraging aggregation: Does the analysis of a longer mtDNA segment provide additional information? In: Bentivegna F, Maffucci F, Mauriello V (Comps) 4th Medit Conf Mar Turtles, Naples, p 73

Karl SA, Bowen BW (1999) Evolutionary significant units versus geopolitical taxonomy: molecular systematics of an endangered sea turtle (genus Chelonia). Conserv Biol 13:990-999

Laurent L, Bradai MN, Hadoud DH, El Gomatai HM (1997) Assessment of sea turtle nesting activities in Libya. Mar Turtle Newsl 76:2-6

- Laurent L, Casale P, Bradai MN, Godley BJ and others (1998) Molecular resolution of marine turtle stock composition in fishery bycatch: a case study in the Mediterranean. Mol Ecol 7:1529-1542

Maffucci F, Kooistra W, Bentiveyna F (2006) Natal origin of loggerhead turtles, Caretta caretta, in the neritic habitat off the Italian coasts, Central Mediterranean. Biol Conserv 127:183-189

Margaritoulis D (1997) Interchange of nesting loggerheads among Greek beaches. In: Epperly S, Braun J (eds) 17th
Annu Sea Turtle Symp. NOAA, Orlando, FL, p 239-241

Margaritoulis D, Argano R, Baran I, Bentivegna F and others (2003) Loggerhead turtles in the Mediterranean Sea: present knowledge and conservation perspectives. In: Bolten A, Witherington B (eds) Loggerhead sea turtles. Smithsonian Books, Washington, DC, p 175-198

McClellan CM, Read AJ (2007) Complexity and variation in loggerhead sea turtle life history. Biol Lett 3:592-594

> Monzon-Arguello C, Rico C, Naro-Maciel E, Varo-Cruz N, Lopez P, Marco A, Lopez-Jurado LF (2010) Population structure and conservation implications for the loggerhead sea turtle of the Cape Verde Islands. Conserv Genet 11:1871-1884

Moran MD (2003) Arguments for rejecting the sequential Bonferroni in ecological studies. Oikos 100:403-405

- Moritz C (1994) Defining 'Evolutionarily Significant Units' for conservation. Trends Ecol Evol 9:373-375

Nielsen JT (2010) Population structure and the mating system of loggerhead turtles (Caretta caretta). PhD dissertation, University of Miami, Coral Gables, FL

Okuyama T, Bolker BM (2005) Combining genetic and ecological data to estimate sea turtle origins. Ecol Appl 15: 315-325

Raymond M, Rousset F (1995) An exact test for population differentiation. Evolution 49:1280-1283

> Reece JS, Castoe TA, Parkinson CL (2005) Historical perspectives on population genetics and conservation of three marine turtle species. Conserv Genet 6:235-251

Reis EC, Soares LS, Vargas SM, Santos FR and others (2010) Genetic composition, population structure and phylogeography of the loggerhead sea turtle: colonization hypothesis for the Brazilian rookeries. Conserv Genet 11: 1467-1477

Revelles M, Carreras C, Cardona L, Marco A and others (2007) Evidence for an asymmetrical size exchange of loggerhead sea turtles between the Mediterranean and the Atlantic through the Straits of Gibraltar. J Exp Mar Biol Ecol 349:261-271

Roberts MA, Schwartz TS, Karl SA (2004) Global population genetic structure and male-mediated gene flow in the green sea turtle (Chelonia mydas): analysis of microsatellite loci. Genetics 166:1857-1870

Schleich HH (1984) Studies on the herpetology of the Kouf National Park and adjacent areas of Cyrenaica. IUCN, Gland

Schroth W, Streit B, Schierwater B (1996) Evolutionary handicap for turtles. Nature 384:521-522

> Serra IA, Innocenti AM, Di Maida G, Calvo S and others (2010) Genetic structure in the Mediterranean seagrass Posidonia oceanica. Disentangling past vicariance events from contemporary patterns of gene flow. Mol Ecol 19: $557-568$

Shamblin B, Dodd M, Bagley D, Ehrhart L and others (2011) Genetic structure of the southeastern United States loggerhead turtle nesting aggregation: evidence of additional structure within the peninsular Florida recovery unit. Mar Biol 158:571-587

> Tamura K, Nei M (1993) Estimation of the number of nucleotide substitutions in the control region of mitochondrial DNA in humans and chimpanzees. Mol Biol Evol 10:512-526

Wallace BP, DiMatteo AD, Hurley BJ, Finkbeiner EM and others (2010) Regional management units for marine turtles: a novel framework for prioritizing conservation and research across multiple scales. PLoS One 5:e15465 